\title{
ENSINO SUPERIOR: ENTRE DOCÊNCIAS E VIOLÊNCIAS
}

\author{
EDUCACIÓN SUPERIOR: ENTRE LA ENSEÑANZA Y LA VIOLENCIA
}

HIGHER EDUCATION: BETWEEN TEACHING AND VIOLENCE

\author{
Mônica Pereira dos SANTOS ${ }^{1}$ \\ Sandra Cordeiro de $\mathrm{MELO}^{2}$ \\ Mylene Cristina SANTIAGO ${ }^{3}$
}

RESUMO: Com base em dados da Comissão de Direitos Humanos e Combate às Violências e da Diretoria de Acessibilidade da Universidade Federal do Rio de Janeiro e nos dados da Diretoria de Ações Afirmativas e Diretoria de Imagem Institucional da Universidade Federal de Juiz de Fora, este artigo tem por objetivo analisar e discutir as violências nas relações entre professores e alunos na perspectiva omnilética (SANTOS, 2013). Partimos de uma revisão de literatura sobre o tema geral da violência em sala de aula no ensino superior e, na sequência, por meio da metodologia de estudo de caso (YIN, 2010), analisamos duas ocorrências nos anos de 2015 e 2017 na UFRJ e na UFJF, respectivamente. Os resultados apontam para a urgência da promoção de propostas balizadoras de culturas, práticas e políticas institucionais de combate às violências nas instituições investigadas.

PALAVRAS-CHAVE: Ensino superior. Inclusão em educação. Violências. Perspectiva omnilética.

RESUMEN: Basado en datos de la Comisión de Derechos Humanos y Lucha contra la Violencia y en la Dirección de Accesibilidad de la Universidad Federal de Río de Janeiro y en datos de la Dirección de Acción Afirmativa y Dirección de Imagen Institucional de la Universidad Federal de Juiz de Fora, este articulo tiene como objetivo analizar y discutir la violencia en la relación entre profesores y estudiantes en la perspectiva omnilectica (SANTOS, 2013). Comenzamos a partir de una revisión de la literatura sobre el tema general de la violencia en el aula en la educación superior y luego, a través de la metodología de estudio de caso (YIN, 2010), analizamos dos acontecimientos en los años 2015 y 2017 en UFRJ y UFJF respectivamente. Los resultados apuntan a la urgencia de promover culturas, prácticas y políticas institucionales para combatir la violencia en las instituciones investigadas.

PALABRAS CLAVE: Educación superior. Inclusión en la educación. Violencia. Perspectiva omnilectica.

1 Universidade Federal do Rio de Janeiro (UFRJ), Rio de Janeiro - RJ - Brasil. Professora Associada. Departamento Fundamentos da Educação. ORCID: https://orcid.org/0000-0002-7057-7804. E-mail: monicapes@gmail.com

2 Universidade Federal do Rio de Janeiro (UFRJ), Rio de Janeiro - RJ - Brasil. Professora Associada. Departamento Fundamentos da Educação. ORCID: https://orcid.org/0000-0002-8437-1671. E-mail: sandracmello@gmail.com

${ }^{3}$ Universidade Federal de Juiz de Fora (UFJF), Juiz de Fora - MG - Brasil. Professora Adjunta. Departamento de Educação. ORCID: https://orcid.org/0000-0003-2769-8421. E-mail: mylenesantiago87@gmail.com 
ABSTRACT: Based on data from the Commission on Human Rights and Violence Combat and the Accessibility Directorate of the Federal University of Rio de Janeiro, as well as on the data from the Affirmative Actions Board and Institutional Image Directorate of the Federal University of Juiz de Fora, this article aims to analyze and discuss the violence in the relationship between teachers and students on the basis of the omniletical perspective (SANTOS, 2013). We start from a literature review on the general theme of classroom violence in higher education and, next, through the case study methodology (YIN, 2010), we analyzed two occurrences in the years 2015 and 2017 at UFRJ and UFJF respectively. The results point to the urgency of the promotion of institutional cultures, policies and practices to combat violence in the institutions investigated.

KEYWORDS: Higher education. Inclusion in education. Violence. Omnilectical perspective.

\section{Introdução}

Este artigo fundamenta-se na sensibilização das autoras, participantes atuantes em contextos como: a Comissão de Direitos Humanos e Combate às Violências - CDHCV/UFRJ, a Diretoria de Acessibilidade da Universidade Federal do Rio de Janeiro - DIRAC/UFRJ, a Diretoria de Ações Afirmativas - DAA/UFJF e a Diretoria de Imagem Institucional da Universidade Federal de Juiz de Fora - DII/UFJF, e, portanto, conhecedoras de denúncias de violências no âmbito institucional. Buscamos, com base nos dados desta Comissão e Diretorias, refletir sobre o desenvolvimento de políticas institucionais que adotem um caráter mais profilático do que remediador da questão da violência nas relações entre professores e alunos no Ensino Superior.

Estes espaços têm, entre suas atribuições, o recebimento de denúncias e a tomada de providências, contudo, os dados ali coletados são confidenciais. Por este motivo, optamos por realizar uma pesquisa exploratória em plataformas de ampla divulgação e coletar casos que foram discutidos pela mídia.

A questão da violência em ambientes educacionais tem sido crescentemente estudada, particularmente em relação à Educação Básica e ao mundo do trabalho, segundo o levantamento exploratório que realizamos no Google Acadêmico, no site G1 e na plataforma Google. Na Educação Superior, as produções têm sido mais frequentes a partir dos últimos 5 anos. Outra observação interessante que fizemos é que a violência em ambientes escolares e universitários tem assumido uma nomenclatura variada para significar basicamente a mesma coisa, como por exemplo: assédio, assédio moral e outras formas de bullying. Segundo o parágrafo $1^{\mathrm{o}}$ da Lei $\mathrm{n}^{\mathrm{o}} 13.185$, de 6 de novembro de 2015 (BRASIL, 2015), que institui o Programa de Combate à Intimidação Sistemática (Bullying), este caracteriza-se por: 
Todo ato de violência física ou psicológica, intencional e repetitivo que ocorre sem motivação evidente, praticado por indivíduo ou grupo, contra uma ou mais pessoas, com o objetivo de intimidá-la ou agredi-la, causando dor e angústia à vítima, em uma relação de desequilíbrio de poder entre as partes envolvidas (BRASIL, 2015, s/p).

Esta mesma Lei ainda classifica a intimidação sistemática em seu artigo $3^{\circ}$ :

Art. $3^{\circ}$ - A intimidação sistemática (bullying) pode ser classificada, conforme as ações praticadas, como:

I - verbal: insultar, xingar e apelidar pejorativamente;

II - moral: difamar, caluniar, disseminar rumores;

III - sexual: assediar, induzir e/ou abusar;

IV - social: ignorar, isolar e excluir;

V - psicológica: perseguir, amedrontar, aterrorizar, intimidar, dominar, manipular, chantagear e infernizar;

VI - físico: socar, chutar, bater;

VII - material: furtar, roubar, destruir pertences de outrem;

VIII - virtual: depreciar, enviar mensagens intrusivas da intimidade, enviar ou adulterar fotos e dados pessoais que resultem em sofrimento ou com o intuito de criar meios de constrangimento psicológico e social (Idem).

Tendo em vista que esta lei abrange uma definição condizente com a fundamentação científica sobre o assunto (NUNES CALDEIRA et al., 2015; GOMES, 2016; BANDEIRA, 2017; FONSECA et al., 2017; MATEUS; PINGOELLO, 2018; SILVA, 2018; SOUZA, 2018), adotaremos, neste artigo, o conceito de violências como sinônimo de assédio, intimidação sistemática e bullying. Discutiremos a produção destes autores nas seções seguintes.

\section{Metodologia}

Este artigo consiste em um estudo exploratório e de caso, pois, como afirmamos, ainda são relativamente escassos os estudos sobre assédio, bullying e violências no ensino superior. Sua produção tem aumentado nos últimos cinco anos, mas ainda permanece incipiente. Neste trabalho adotamos a definição proposta por Gil (2002, p. 41), para quem as pesquisas exploratórias:

[...] têm como objetivo proporcionar maior familiaridade com o problema, com vistas a torná-lo mais explícito ou a constituir hipóteses. Pode-se dizer que estas pesquisas têm como objetivo principal o aprimoramento de idéias ou a descoberta de intuições. Seu planejamento é, portanto, bastante flexível, de modo que possibilite a consideração dos mais variados aspectos relativos ao fato estudado. $\mathrm{Na}$ maioria dos casos, essas pesquisas envolvem: (a) levantamento bibliográfico; (b) entrevistas com pessoas que tiveram 
experiências práticas com o problema pesquisado; e (c) análise de exemplos que "estimulem a compreensão" (SELLTIZ et al., 1967, p. 63).

Neste sentido, além do levantamento bibliográfico sobre o assunto, os casos foram coletados nos sites do G1 e no Google por meio do uso das palavras-chave "denúncia UFJF" e “denúncia UFRJ”, enquadrando-se no tipo (c) definido por Gil, ao citar Selltiz (exemplos que estimulem a compreensão). Encontramos, no total, desde 2015, cerca de oito casos veiculados em sites de jornalismo para as duas universidades, dos quais selecionamos dois casos para discussão no presente artigo.

O segundo delineamento utilizado para esta pesquisa foi o estudo de caso. Yin (2010) provê uma definição dupla para o estudo de caso em geral, para só então classificá-lo. Segundo o autor:

O estudo de caso é uma investigação empírica que investiga um fenômeno contemporâneo em profundidade e em seu contexto de vida real, especialmente quando os limites entre o fenômeno e o contexto não são claramente evidentes e a investigação do estudo de caso enfrenta a situação tecnicamente diferenciada em que existirão muito mais variáveis de interesse do que pontos de dados, e, como resultado, conta com múltiplas fontes de evidência, com os dados precisando convergir de maneira triangular, e como outro resultado beneficia-se do desenvolvimento anterior das proposições teóricas para orientar a coleta e a análise de dados (p. 39-40).

Para a análise dos dados, elegemos a perspectiva Omnilética (SANTOS, 2013), pois se trata de uma perspectiva que proporciona aos pesquisadores uma análise a partir de diferentes pontos de vistas, na medida em que considera, simultaneamente, cinco dimensões: a das culturas, das políticas, das práticas, da dialética e da complexidade. Parte do princípio de que a vida humana (e social) se manifesta por meio destas dimensões, as quais, por sua vez, se entrelaçam constante e incessantemente, ora em relação assimétrica em que uma(s) se sobrepõem à(s) outra(s), a depender de quem olha e como olha, ora em relação mais aparentemente simétrica, em que se percebe cada uma delas com a mesma intensidade, também dependendo de quem e como se olha para os fenômenos em análise.

Especificamente, cada dimensão traz consigo oportunidades de análise a partir de um ponto, a saber: a dimensão das culturas propõe um olhar sobre os valores, os gostos, o que se acredita como bom, ruim, bonito, feio. A dimensão das políticas oferece um olhar sobre as regras, as leis, os combinados e as intenções que estão presentes em um contexto de análise. A dimensão das práticas sugere um olhar sobre o que efetivamente é feito, como a ação cotidiana. Entendemos que a relação entre culturas, políticas e práticas não é linear nem tampouco livre de tensões. Ao contrário, é cheia de contradições. Por este motivo, à 
tridimensionalidade proposta por Booth e Ainscow (2012), acrescentamos (SANTOS, 2013) mais duas dimensões: a da complexidade e da dialética. A dimensão da complexidade, com base nos escritos de Morin (2011), orienta um olhar para estas ditas contradições e criva a relação tridimensional com o paradigma da incerteza, trazendo um grau instituinte de provisoriedade nos conhecimentos e relações estabelecidos até então. A dimensão da dialética ilumina a tridimensionalidade para uma perspectiva de transformação das contradições inerentes e criação de novas possibilidades, complexas e dialéticas, de arranjos entre culturas, políticas e práticas.

Desta forma, pensar e ver omnileticamente significa reconhecer que o mesmo evento analisado pode assumir diferentes possibilidades de interpretação ao mesmo tempo e posteriormente. É compreender que a realidade são realidades, e que a única coisa que, seguramente, cerca e garante a produção de qualquer conhecimento, é a incerteza que este engendra. Isto coloca os pesquisadores em um constante estado de alerta, algo que consideramos muito benéfico, tendo em vista, inclusive, o tema deste artigo, o qual, por sua vez, não se distancia do cotidiano da academia: a arrogância (e consequentes práticas de violência) que podemos desenvolver ao considerarmos nossas perspectivas como certas e verdadeiras. Neste sentido, a análise omnilética pode contribuir para o que consideramos um saudável ato com o qual pesquisadores deveriam estar comprometidos: a desafiar, moto contínuo, o auto centramento (vaidade) acadêmico.

\section{Ensino superior e docências}

Uma das principais características do modelo de Educação Superior adotado no Brasil é a da autonomia universitária. Com o propósito de lançar orientações sobre Direitos Humanos (DH) para que os países norteassem suas instituições, padrões e procedimentos, a UNESCO lançou, em 2003, o documento A Guide to human rights: institutions, standards, procedures (Um Guia para os DH: instituições, padrões e procedimentos). O intuito deste documento, além de ser o de sensibilizar gestores, políticos e demais interessados na causa dos $\mathrm{DH}$, foi o de fortalecer o papel da educação como principal agente propagador dos princípios necessários ao desenvolvimento de povos que adotem tais princípios e os programem em suas políticas.

O referido documento consiste em um tipo de Dicionário em que se definem vários termos importantes à temática de $\mathrm{DH}$, sendo que o primeiro termo é, justamente, "Liberdade Acadêmica" (ACADEMIC FREEDOM). Vejamos o que diz a definição: 
Liberdade acadêmica pode ser definida como a liberdade de pesquisadores, professores e alunos para ensinar, estudar e buscar conhecimento e pesquisa sem interferência ou restrição excessiva da lei, regulamentações institucionais ou pressão pública. A liberdade acadêmica está intimamente relacionada com o direito à educação [...]. Também está intimamente ligada à liberdade de opinião e expressão, à liberdade de investigação científica e à liberdade de procurar, receber e transmitir informações. A justificativa para a liberdade acadêmica reside em seus benefícios para a sociedade, o que significa que os interesses de uma sociedade são melhor servidos quando o processo educacional leva ao avanço do conhecimento e o último progride melhor sem quaisquer restrições sobre a pesquisa.

[...] A liberdade acadêmica é composta pelos seguintes direitos: [...]; o direito dos alunos a estudarem, a escolherem seu campo de estudo, a participarem da organização do processo educativo e a receberem reconhecimento oficial do conhecimento e da experiência adquirida [...] (UNESCO, 2003, p. 1-2, grifo nosso).

O motivo pelo qual trouxemos esta definição ao presente artigo reside no fato de que este conceito se aplica a todos os segmentos universitários conhecidos no Brasil (docentes, técnicos e estudantes), além de, conforme frisamos em nossos grifos, trazerem à tona o lado específico dos direitos estudantis. Observemos que ali está posto que a este segmento da universidade deve-se o reconhecimento de seus conhecimentos e experiências. Entretanto, perguntamos: isto é tomado como prática comum em nossas universidades? Cremos que não.

O que queremos pontuar? A ideia de que, a despeito desta e de tantas outras normatizações, nacionais e internacionais, referentes aos DH (dos quais, obviamente, estudantes fazem parte), temos observado, no Brasil, que tais direitos nem sempre são respeitados, inclusive por parte de nossos docentes, quando o foco são nossos estudantes.

Decerto que o Brasil, já de longa data, é reconhecido internacionalmente por ser um dos países que mais violam os DH, para nosso desespero e tristeza. No entanto, esta "fama", até aonde podemos afirmar, nunca se estendeu à Educação Superior. Sabemos que casos de assédio e desrespeito aos direitos sempre existiram, inclusive na Academia, e que tais casos podem ocorrer com quaisquer dos seus três segmentos. Porém, até o presente, não se havia identificado um número tal de casos que justificasse maiores investigações e reflexões a respeito da temática, mas agora temos a impressão de que estamos acordando para isso. Em nossa visão, esta premência fica ainda maior quando pensamos o segmento da base da pirâmide hierárquica das instituições universitárias: os estudantes, que além de vitimizados por servidores em geral (docentes e técnicos), se vitimizam entre si.

Os/as professores, e dentre eles os universitários, sabidamente, constituem sujeitos de uma das profissões mais desgastantes da atualidade. É bem provável que as próprias condições de trabalho, atualmente e cada vez mais tão precarizadas, combinadas com a 
multiplicidade crescente de tarefas que estes profissionais são cobrados a desempenhar, expliquem, em parte, o fato de professores serem tanto vítimas quanto algozes do bullying. Mesmo assim, explicar não pode servir para justificar. É importante, portanto, sabermos o que os estudos dizem a respeito daqueles professores que perpetram o bullying, tendo em vista levantarmos a questão para amplo debate, já que está aparente que este segmento também é responsável por cometer violências.

\section{Ensino superior e violências}

Nesta seção, apresentaremos nossa revisão bibliográfica sobre o tema das violências, com base em busca realizada no Google Acadêmico a partir de 2015. Optamos por este caminho por se tratar de site já bastante reconhecido pelas comunidades científicas, e optamos por este período tendo em vista que o caso mais antigo a ser tratado data de 2015.

Em 2015, Mateus e Pingoello realizaram um estudo em que buscaram investigar a ocorrência de bullying no Ensino Superior. Buscaram, também, efetivar uma análise estatística acerca da relação entre as seguintes variáveis: Curso de Graduação, Idade, Etapa de Graduação e Sexo na ocorrência do bullying. Seus resultados apontaram para uma relação significativa das variáveis: Curso de Graduação, Idade e Etapa de Graduação com o fenômeno bullying.

Em que pese os autores alertarem para que não se confunda bullying com racismo, assédio sexual ou moral ou agressão pontual, eles reconhecem que o bullying abrange todos estes (e outros) atos, o que condiz com nossa definição. Dizem os autores que, para que se caracterize como bullying, é preciso haver referência específica a uma "intimidação exercida sistematicamente pelo mais forte sobre o mais fraco utilizando-se de comportamentos racistas, discriminatórios e ofensivos" (MATEUS; PINGOELLO, 2015, p. 31). Os autores continuam explicando que:

O Bullying pode ser definido como conjunto de atitudes agressivas, repetitivas e intencionais adotadas por uma pessoa ou um grupo de pessoas com finalidade de causar angústia, dor e sofrimento. Tal forma de agressão ocorre em relação desigual de poder, culminando em real situação de desvantagens para suas vítimas (idem).

Com esta definição, fica claro que o bullying não é um fenômeno apenas escolar, mas que pode acontecer também entre adultos e em variados locais de estudo e/ou de trabalho.

A pesquisa de Mateus e Pingoello (2015) verificou que, diferentemente dos estudos com os níveis Fundamental e Médio da educação, no Superior o sexo não foi uma variável 
significativa. Tendo em vista que nossos casos (e muitos outros), bem como estudos na Educação Básica (MOURA et al., 2011), têm apontado a variável sexo como um diferencial, cremos que maiores investigações precisam ser feitas sobre esta variável. A este propósito, inclusive, Gadelha (2019, p. 358) afirma que:

Diversos estudos reportaram que tanto os agressores quanto as vítimas de bullying são, em maior parte, do sexo masculino. No entanto, há também estudos defendendo que a variação entre os gêneros é devido ao tipo de agressão praticada, sendo a prevalência do bullying equivalente entre homens e mulheres.

Outro aspecto preocupante da pesquisa de Mateus e Pingoello (2015) refere-se ao fato de que a idade apresenta correlação com o bullying: dos $25 \%$ da amostra de estudantes entrevistados que declararam sofrer bullying, 53\% estava no primeiro período da graduação, sendo que o tipo mais frequente de bullying sofrido foi o verbal, que afetou $68 \%$ desses participantes, o que confere com estudos sobre a temática no nível Básico de educação (MOURA et al., 2011).

Por fim, o dado mais alarmante do referido estudo foi o fato de que $76 \%$ da amostra que declarou sofrer bullying relatou tê-lo sofrido dentro da sala de aula, contradizendo dados sobre a Educação Básica, cujas pesquisas (MOURA et al., 2011) apontam que o local predominantemente comum é o pátio. Estranhamos que os autores sequer consideraram a hipótese, em seu artigo, de que o praticante possa ser o próprio professor, pois nos parece que é exatamente isso que acontece no ensino Superior. Neste sentido, seria muito importante que as pesquisas futuras sobre a temática trouxessem os docentes - e as docências - como objeto central de interesse da pesquisa.

Buscando compreender de que forma o bullying se caracteriza na universidade, Gadelha (2019) realizou uma revisão sistemática de literatura com base em 5 diferentes bancos de dados, incluindo o ERIC (Education Resources Information Center), buscando produções de 2009 a 2018 e utilizando os descritores "bullying” AND “universities". A autora chegou a 54 trabalhos, dos quais selecionou 14 produzidos na América do Sul.

Como exemplo do que foi encontrado por Mateus e Pingoello (2015), a autora também revelou que a forma mais comum de bullying presente nos estudos que investigou, no nível universitário, é o verbal. Com efeito, de modo geral, este estudo confirma praticamente todos os aspectos da pesquisa de Mateus e Pingoello (2015), exceto por um fator: o de gênero. Ao que parece esta variável tem se tornado mais significativa em pesquisas mais recentes. 
Outra variável importante levantada neste estudo foi a presença ou não de deficiência caracterizando o perfil das vítimas. A autora descobriu que as pessoas com deficiência, em particular aquelas com deficiência física, têm maior tendência a sofrer violências do que outras.

Gadelha (2019) finaliza seu artigo recomendando que as universidades adotem medidas e políticas antibullying, e que estas levem em consideração, especialmente, as variáveis de gênero, orientação sexual, raça, condição socioeconômica e deficiência, considerados pela autora como as características mais prováveis inerentes à vítima. Uma vez mais, chamamos a atenção para o fato de que a possibilidade de agressão por parte de professores sequer foi cogitada neste estudo.

Outro estudo importante de se mencionar é o de FONSECA et al., (2017), em uma survey realizada com 773 alunos de Ciências Contábeis (cursando do $1^{\circ}$ ao $10^{\circ}$ período) de uma universidade federal em 2014, que buscou avaliar o bullying sob a perspectiva das vítimas, dos praticantes e das testemunhas. Os autores identificaram que o bullying é mais praticado por sujeitos do sexo masculino, que é visto pelas testemunhas como brincadeira, que não é denunciado nem pelas vítimas nem pelas testemunhas e que sua maior ocorrência é na sala de aula, confirmando muito do que já foi aqui discutido.

Por outro lado, este artigo apresenta um diferencial importante: a consideração de que professores e educadores podem ser agressores, ou bullies, tanto quanto qualquer outro sujeito. Para $29 \%$ da amostra, a maior incidência de bullying se dá em sala de aula, mas os mesmos se responsabilizaram apenas por $27 \%$ destes atos, o que levanta a séria pergunta: Quem mais, então, na sala de aula, poderia estar praticando o bullying? Ou teria sido que parte destes alunos mentiu?

SILVA (2018) estudou 310 universitários (de graduação e pós-graduação) para entender como o bullying afeta a vida dos universitários. 22\% de sua amostra relataram sofrer bullying, um número bastante aproximado ao estudo de Mateus e Pingoella (2015). Os achados de Silva também corroboram os dos estudos anteriormente mencionados: a autora chama ainda a atenção para o fato de que a maioria das vítimas sofre silenciosamente, e ainda, que as testemunhas relevam a situação tentando considerá-la como brincadeira - fator este, aliás, pontuado como altamente inadequado e como sendo de imediata necessidade de intervenção em quase todos os artigos que encontramos.

A novidade apresentada por este artigo, e que acompanha o de Fonseca (2017), é a consideração da possibilidade de que professores também cometam atos de violências (bullying), assim como que os agredidos também são agressores: 
É utópico acreditar que estudantes universitários apresentam maior capacidade de defesa, eles sofrem abusos por parte de colegas e também da Equipe Docente, mas também agridem, ignoram, discriminam e em alguns casos, até matam por não suportarem mais serem humilhados (GARCIA; MARTA; VECCHIATTI, 2013 apud SILVA, 2017, p. 142).

Em outras palavras, por mais indesejável, antiético e errado que seja, nossa revisão de literatura permite que pelo menos desconfiemos, com certa segurança, de que professores também são agressores. E foi justamente por isso que nos propusemos a trabalhar este aspecto do bullying e das violências no ensino superior; o de quando o agressor é o/a docente.

\section{Os casos}

Optamos por apresentar casos que ganharam visibilidade na mídia, por não infringirem questões éticas e por manterem o anonimato dos envolvidos. Os casos selecionados denotam a multidimensionalidade e complexidade das relações e circunstâncias que envolvem a delicada e tênue linha que Paulo Freire (1996) chama de bom senso, que significa o equilíbrio entre a autoridade e a liberdade. Caso a imaginária balança penda mais para um lado, nós professores, corremos o risco de agir de forma licenciosa ou autoritária. O que isso quer dizer? Que a tarefa docente requer grande equilíbrio e ética, no sentido de impedir que distorções ou deturpações entre os princípios da autoridade e liberdade não incorram em qualquer tipo de violência ou abuso de poder.

Caso 1: UFJF nega recurso e demite professor acusado de assédio e agressão (G1, Zona da Mata, 21/02/2017)

O Conselho Superior da Universidade Federal de Juiz de Fora (UFJF) negou o pedido de recurso do professor da Faculdade de Odontologia, que foi acusado por agressão e assédio a uma estudante. Na reunião desta terça-feira (21), que tratou do Processo Administrativo Disciplinar (PAD) dele, ficou decidido pela demissão do docente. A instituição já havia analisado o caso e decidido em janeiro, mas o professor, de 61 anos, recorreu do resultado.

A defesa do professor informou que ele buscará reparação via Justiça. A vítima denunciou o caso em junho de 2016, alegando que durante uma aula, ela o chamou pelo nome e ele pediu que ela saísse da sala. Em seguida, ainda de acordo com aluna, ele a trancou, a agarrou pelos braços e colocou o corpo próximo ao dela. Além do processo administrativo, outra investigação da denúncia está em andamento na Polícia Civil.

Em meio ao andamento do processo, ele sofreu um acidente de motoneta e ficou afastado da universidade por dois meses, reassumindo as funções em agosto. Em novembro, ele foi afastado do cargo, como forma de preservar o andamento do processo interno. De acordo com o Boletim de Ocorrência (BO), o professor disse que a aluna não poderia chamá-lo pelo nome e teria que mostrar respeito, visto que era uma "reles acadis" (acadêmica) e não

RIAEE - Revista Ibero-Americana de Estudos em Educação, Araraquara, v. 15, n. esp. 2, p. 1449-1464, ago. 2020. e-ISSN: $1982-5587$. 
poderia estar junto aos "docs" (doutores). Após soltá-la, ela continuou na aula e o professor passou a ofendê-la dizendo que a universitária não se formaria no fim do ano porque não teria competência para passar em três disciplinas com ele, também conforme o BO.

De acordo com o relato da estudante, assim que a aula do dia 23 de junho terminou, ela chamou os pais e procurou a direção da Faculdade de Odontologia para formalizar a denúncia. Ainda segundo a estudante, ele já teria a assediado antes. A Ouvidoria foi chamada e a Polícia Militar (PM) acionada para fazer o registro da ocorrência. De acordo com a PM, a direção da faculdade informou que o professor não estava em ambiente acadêmico no momento do registro da ocorrência e não foi encontrado para falar sobre a denúncia.

Esta denúncia aponta para um caso de violência em sala de aula, cometida por um professor que se ofendeu quando a aluna o chamou pelo próprio nome. Segundo ele, uma "reles acadis" (acadêmica) não poderia estar junto aos "docs" (doutores). Sua indignação o levou a agredi-la física e moralmente, e a ameaçá-la de reprovação.

Este caso nos remete à questão cultural das vaidades no ambiente acadêmico e à visão (também cultural) de que o distanciamento entre alunos e professores deve fazer parte do processo de aprendizagem. Outro ponto importante está nos procedimentos institucionais acionados (as práticas e políticas): a formalização da denúncia pela estudante na direção da unidade, o contato com a ouvidoria e o acionamento imediato da polícia militar. Após estes procedimentos a unidade abriu um processo administrativo disciplinar e exonerou o docente. Estas ações sugerem o comprometimento (culturas) da unidade com as questões estudantis, principalmente por acolherem imediatamente a denúncia de uma aluna.

No geral, a partir de um olhar omnilético, vemos que tanto as culturas, quanto as políticas e as práticas aqui apontadas se mesclam e se hibridizam umas com as outras, em relações tanto divergentes quanto convergentes, o que aponta não apenas para o caráter dialético com que tais dimensões se 'relacionam', quanto para o caráter complexo, na medida em que cada nova configuração relacional entre estas dimensões (produzidas em e por cada novo momento histórico) pode abrir novas portas para que se construam novas culturas, práticas e políticas sobre a matéria.

Cabe ressaltar que a resposta dada pela instituição não se tratou de resposta comumente encontrada nas reportagens que investigamos. Em geral, o que se faz é silenciar ou tratar o caso "internamente", ou em sigilo.

Caso 2: Professor [da UFRJ] é acusado de agredir aluno (Site Band Rio, 26/05/15)

Enquanto estudantes dos três cursos da Faculdade de Administração e Ciências Contábeis (FACC) se reuniam na Cidade Universitária da UFRJ, na 
Ilha do Fundão, ontem (25), com o reitor [...] para denunciar o autoritarismo, ameaças, perseguição, criminalização do movimento estudantil e assédio moral, cometidos pelo Diretor da FACC, acontecia na Praia Vermelha a reunião do departamento de Administração. Nessa reunião o diretor agrediu o estudante [...] sem haver qualquer motivo. Causando espanto e medo entre os professores na sala, o diretor também tomou o seu celular de sua mão e o arremessou no chão, pisoteando em seguida.

As imagens foram feitas por um dos estudantes através do aparelho celular. Inicialmente, a câmera está filmando apenas o chão. No momento seguinte, há uma confusão e o vídeo mostra o professor tentando pegar o celular das mãos de [...], aluno de Administração.

Os alunos vão entrar com um pedido para a saída do docente da direção da Escola. Segundo os alunos, o professor já havia demonstrado autoritarismo em diversos momentos em que ameaçou estudantes. Ainda segundo os alunos, o diretor decretou 3 dias de "nojo" na Faculdade de Administração. A UFRJ informou que deve instaurar um processo disciplinar para apurar a conduta do servidor. Ele não foi encontrado para comentar o caso.

Esta denúncia de 2015 se apresenta muito atual, à medida que trata de abuso de autoridade e violência física. Neste caso, a agressão é perpetrada pelo diretor da Faculdade contra um aluno membro de movimento estudantil que participava da reunião de Departamento. Com esta ação o diretor provou que o ato dos estudantes junto ao reitor procedia, já que mostrou a mesma violência a respeito da qual vinha sendo denunciado.

A cultura aqui posta é a de que contra a autoridade toda ação é subversiva, merecedora de violência física e apreensão e destruição de objetos pessoais. É a concepção de que à autoridade cabe como resposta apenas a obediência. Esta interpretação está condizente com os estudos aqui discutidos (NUNES CALDEIRA et al., 2015; GOMES, 2016; BANDEIRA, 2017; FONSECA et al., 2017; MATEUS; PINGOELLO, 2018; SILVA, 2018; SOUZA, 2018), segundo os quais os sujeitos que praticam o bullying são parte de relações desiguais de poder, estando no topo da hierarquia, e abusam do mesmo, deliberadamente.

Fato é que a situação gera incômodo, não só em nós, mas nos alunos membros do movimento estudantil, principalmente por se tratar de um ambiente acadêmico que deveria se pautar pelo diálogo e pelas trocas, pela reflexão, pelo estudo e pela pluralidade de pensamentos. Contudo, para que haja esta relação positiva, é preciso que a força dê lugar à palavra. A complexidade está na possibilidade de sujeitos com vidas e pensamentos tão diferentes se enxergarem, se respeitarem, cruzarem suas perspectivas num mesmo objetivo de aprendizagem, de formação.

Perguntamo-nos: quem esta faculdade, representada por este diretor, pretende formar? Que tipo de cultura um docente 'transfere' aos estudantes quando se comporta de tal modo? Que tipo de política institucional isto pode refletir? Para que práticas futuras isto pode apontar? Quando o diretor pega e quebra o celular do aluno, o que ele está interrompendo é a 
gravação de sua imagem, agindo de forma agressiva. Certamente, ele saberia que apenas destruía uma fonte de gravação e que haveria outras, mas sua raiva e indignação o levaram a este desvario. $\mathrm{O}$ ato dos alunos ameaçava a sua autoridade de diretor porque questionava suas ações. Ali não coube diálogo: é a cultura do autoritarismo, a política do silenciamento, a prática da violência em ação.

Pelo olhar omnilético podemos conceber, ainda assim, que a situação pode (e deve ter surtido) surtir mudanças, principalmente pela pressão no sentido oposto, ou seja, pela reação de combate à agressão cometida. Isto nos mostra o caráter já mencionado da omnilética, que defende que culturas, políticas e práticas estão imersas numa dialeticidade e complexidade tais que fica impossível não reconhecer que a vida social e humana é pura incerteza e movimento - contraditório e não.

\section{Considerações finais}

Com base nas vivências das nossas participações nas citadas Comissão e Diretorias e na análise omnilética, percebemos que casos como os que analisamos aqui acontecem com certa regularidade. O que os diferencia são os encaminhamentos dados pelas Universidades e a efetivação da denúncia pela vítima. Na UFRJ cada unidade possui um grau de autonomia, que muitas vezes permite que sejam colocados "panos quentes" sobre os casos denunciados, a menos que a vítima acesse a ouvidoria. Neste caso, a conclusão da denúncia retorna a esta instância, superior à da unidade, tornando-se conhecida pela gestão, que tem a opção de abrir um processo administrativo disciplinar - PAD, independente de interesses eventualmente corporativistas que possam ser identificados.

Na UFJF as denúncias são feitas na Ouvidoria, que funciona como uma porta de entrada para acolher e escutar de forma qualificada e ativa as demandas do cidadão, promovendo a sua participação na gestão pública. Dessa forma, ela exerce o papel de portavoz do solicitante na instituição. A Ouvidoria da UFJF é responsável por receber, acolher e encaminhar as demandas que digam respeito ao relacionamento do cidadão com o Colégio de Aplicação João XXIII, os campi de Juiz de Fora e Governador Valadares. No caso do Hospital Universitário (HU), existe uma ouvidoria própria, mas dependendo da característica da solicitação, ela também é acompanhada e monitorada pela Ouvidoria Geral.

Sensibilizadas por estas realidades, e com base nos estudos apresentados, consideramos que, cientes destas condições adversas às vítimas, as universidades precisariam desenvolver mecanismos e estratégias de combate às violências, inclusive aquelas perpetradas 
por aqueles que mais dispõem de poder e status na hierarquia universitária. No caso da UFRJ, um exemplo destes mecanismos (para além, é claro, da própria Ouvidoria), foi a constituição da Comissão de Direitos Humanos e Combate às Violências, em 2017, e que tem, desde então, se ocupado de uma grande variedade de casos, para nosso desgosto. No caso da UFJF, questões específicas relacionadas a assédio, discriminação, preconceito, violência e opressão vivenciadas no ambiente universitário, desde 2014, são tratadas e acolhidas pela Ouvidoria Especializada, diretamente ligada à Diretoria de Ações Afirmativas (Diaaf).

Se, por um lado, a própria existência destas ações significa que tais casos estão presentes no cotidiano das instituições educacionais, por outro lado, ela também representa uma importante forma de dar visibilidade à questão das violências, o que abre a possibilidade de se construir debates, mobilizar coletivos, esclarecer e reeducar nossa população, planejar apoio e, quem sabe, melhorar esta excludente e indesejável realidade.

AGRADECIMENTOS: Capes, CNPq, FAPERJ.

\section{REFERÊNCIAS}

BANDEIRA, L. M. Trotes, assédios e violência sexual nos campi universitários no Brasil. Revista Gênero, v. 17, n. 2, 2017.

BOOTH, T.; AINSCOW, M. Index para a inclusão: desenvolvendo a aprendizagem e a participação nas escolas. Bristol: CSIE, 2011.

BRASIL. Lei n. 13.185, de 6 de novembro de 2015. Institui o programa de combate à intimidação sistemática (Bullying). Diário Oficial da União, Brasília, 09 nov. 2015. Disponível em: http://www.planalto.gov.br/ccivil_03/_ato2015-2018/2015/lei/113185.htm. Acesso: 23 jul. 2019.

BRASIL. MEC. INEP. Ações discriminatórias no âmbito escolar. Projeto de estudo sobre ações discriminatórias no âmbito escolar, organizadas de acordo com áreas temáticas, a saber, étnico racial, gênero, orientação sexual, geracional, territorial, de necessidades especiais e socioeconômica. Brasília, 2009. Disponível em:

http://www.mp.sp.gov.br/portal/page/portal/Educacao/Doutrina/Pesquisa\%20Diversidade_Su mario\%20resultados\%20descritivos.pdf. Acesso: 23 jul. 2019.

CALDEIRA, S. N. et al. Estudantes do ensino superior, praxe académica e satisfação com a vida. Configurações. Revista de sociologia, n. 16, p. 97-112, 2015.

FERNÁNDEZ, J. M. La noción de violencia simbólica en la obra de Pierre Bourdieu: una aproximación crítica. Cuadernos de Trabajo Social., v. 18, p. 7-31, 2005. Disponível em: http://biblioteca.ues.edu.sv/revistas/10800248.1.pdf. Acesso em: 23 de jul. 2019. 
FONSECA, K. B. C. et al. Incidência do bullying nos cursos de administração e ciências contábeis. Psicologia Escolar e Educacional, v. 21, n. 1, p. 79-92, 2017.

FREIRE, P. Pedagogia da Autonomia: Saberes necessários à prática educativa. Rio de Janeiro: Paz e Terra, 1996.

GADELHA, M. do S. V. et al. Bullying nas instituições de ensino superior: revisão sistemática/Bullying in higher education institutions: systematic review. Revista Multidisciplinar e de Psicologia, v. 13, n. 44, p. 357-373, 2019.

GIL, A. C. Como elaborar projetos de pesquisa. 4. ed. São Paulo: Atlas, 2002.

GOMES, G. Microagressões no ensino superior nas vias da educação matemática. Revista Latinoamericana de Etnomatemática: Perspectivas Socioculturales de la Educación Matemática, v. 9, n. 3, p. 44-76, 2016.

MATEUS, G. A. P.; PINGOELLO, I. Ocorrência de bullying no ensino superior. Revista Uningá Review, [S.1.], v. 22, n. 3, jan. 2018. ISSN 2178-2571. Disponível em:

http://revista.uninga.br/index.php/uningareviews/article/view/1631. Acesso em: 21 jul. 2019.

MORIN, E. Introdução ao pensamento complexo. Porto Alegre: Sulina, 2011.

MOSCARDINI, G. Professor é acusado de agredir aluno. Band Rio, 26 maio 2015.

Disponível em: https://bandrio.band.uol.com.br/noticias/100000753210/durante-uma-reuniaoprofessor-agride-aluno-.html.html.html.html. Acesso em: 30 set. 2019.

MOURA, D. R. et al. Prevalência e características de escolares vítimas de bullying. J.

Pediatr. (Rio J.), Porto Alegre, v. 87, n. 1, 2011. Disponível em:

http://www.scielo.br/scielo.php?script=sci_arttext\&pid=S0021-

75572011000100004\&lng=en\&nrm=iso. Acesso em: 23 jul. 2019. DOI:

http://dx.doi.org/10.1590/S0021-75572011000100004

SANTOS, M. P. Dialogando sobre inclusão em educação: contando casos (e descasos). Curitiba: CRV, 2013.

SILVA, R. B. A Prática do bullying nas instituições de nível superior: um estudo no distrito federal. Projeção, Direito e Sociedade, v. 9, n. 1, p. 150-158, 2018.

SOUZA, C. D.de. Diagnóstico do enfrentamento ao assédio moral em uma instituição federal de ensino superior. 2018. 150 f. Dissertação (Mestrado Profissional em Gestão de Processos Institucionais) - Universidade Federal do Rio Grande do Norte, Natal, 2018.

UFJF. Conheça como funciona a Ouvidoria Geral da UFJF. Disponível em: https://www2.ufjf.br/noticias/2017/08/16/conheca-como-funciona-a-ouvidoria-geral-da-ufjf/. Acesso 30 de set. 2019.

UFJF. UFJF nega recurso e demite professor acusado de assédio e agressão. G1, 21 fev. 2017. Disponível em: http://g1.globo.com/mg/zona-da-mata/noticia/2017/02/ufjf-nega-recurso-edemite-professor-acusado-de-assedio-e-agressao.html. Acesso 30 de set. 2019. 
UNESCO. A guide to human rights: institutions standards, procedures. 2003.

YIN, R. Estudo de caso: planejamento e métodos. 4. ed. Porto Alegre: Bookman, 2010.

\section{Como referenciar este artigo}

SANTOS, M. P.; MELO, S. C.; SANTIAGO, M. C. Ensino Superior: entre docências e violências. Revista Ibero-Americana de Estudos em Educaçãa, Araraquara, v. 15, n. esp. 2, p. 1449-1464, ago. 2020. e-ISSN: 1982-5587. DOI: https://doi.org/10.21723/riaee.v15iesp2.13799

Submetido em: 30/08/2019

Revisões requeridas: $30 / 11 / 2019$

Aprovado em: 02/02/2020

Publicado em: 01/08/2020 